\title{
Growth of Carbon Nanofibers in Phenolic Resin for Carbon-Contained Refractory Using Different Catalysts
}

\author{
Jun Yu, Huizhong Zhao, Han Zhang, Jingjie Li, and Xiongfeng Ding \\ The State Key Laboratory of Refractories and Metallurgy, Wuhan University of Science and Technology, Wuhan 430081, China \\ Correspondence should be addressed to Jun Yu; yjwust@163.com
}

Received 30 December 2016; Accepted 30 March 2017; Published 26 April 2017

Academic Editor: Stefano Bellucci

Copyright (C) 2017 Jun Yu et al. This is an open access article distributed under the Creative Commons Attribution License, which permits unrestricted use, distribution, and reproduction in any medium, provided the original work is properly cited.

\begin{abstract}
Various phenolic resins modified with carbon nanofibers were prepared using $\mathrm{Fe}\left(\mathrm{NO}_{3}\right)_{3}, \mathrm{Co}\left(\mathrm{NO}_{3}\right)_{2}$, and $\mathrm{Ni}\left(\mathrm{NO}_{3}\right)_{3}$ as catalyst, respectively. The influences of different catalysts on the phase, microstructure evolution, and oxidation resistance of the modified phenolic resin were investigated by X-ray diffraction analysis, field-emission scanning electron microscopy, and thermal gravimetric analysis. The results showed that, compared with a single catalyst, the mixed catalysts $\left(\mathrm{Co}\left(\mathrm{NO}_{3}\right)_{2}: \mathrm{Fe}\left(\mathrm{NO}_{3}\right)_{3}=1: 1\right)$ promoted the growth of the carbon nanofibers, which have the higher crystallinity, homogeneous dispersion, and nonagglomeration. These carbon nanofibers can effectively reduce carbon losses, increase char yield, and fill the holes in the thermal cracking process of phenolic resins.
\end{abstract}

\section{Introduction}

Carbon-contained refractories are widely used in converter, $\mathrm{AC}$ arc furnace, and external refining equipment due to their good characteristics [1,2], for example, fire resistance, erosion resistance, thermal shock resistance, and high temperature creep. Phenolic resin (PR) is an important binder of carboncontained refractory, which has high fixed carbon rate as well as high wettability with graphite and oxide. The phenolic resin-pyrolysed carbon can not be wetted by molten slag and demonstrates high thermal conductivity [3]. However, it is an isotropic glassy carbon with high brittleness, which affects possible improvement of the thermal shock resistance of carbon-contained refractory $[4,5]$. To improve the crushing and bending strengths before and after coking, as well as the oxidation resistance and thermal of carbon-contained refractory, several studies have focused on PR modification by adding various antioxidants, such as $\mathrm{Al}, \mathrm{Si}, \mathrm{SiC}$, and $\mathrm{B}_{4} \mathrm{C}$ [6-8]. However, these modification methods still need to be further optimized.

Carbon nanofibers (CNFs) have superior mechanical properties and excellent thermal properties $[9,10]$, and the pyrolysis process of PR is suitable to form CNFs in situ $[11,12]$. Compared with the traditional external addition methods, the in situ formation of CNFs can transform the glassy isotropic carbon of the phenolic resin-pyrolysed carbon into graphitic carbon by catalytic graphitization. Moreover, the CNFs can uniformly disperse in PR and improve high temperature oxidation resistance of $\mathrm{PR}[13,14]$. In this report, the influences of the different catalysts on the phase, microstructure evolution, and oxidation resistance of the modified phenolic resin were investigated systematically.

\section{Materials and Methods}

The appropriate ratios of phenolic resin powder and nitrate catalyst were dissolved in ethylene glycol to form a mixture precursor. And the precursor was stirred by a propeller stirrer (speed of $6.5-7.5 \mathrm{kr} / \mathrm{min}$ ) for 1 hour. Then, the stirred mixture precursor was buried in carbon with heat treatment at $1100^{\circ} \mathrm{C}$ for $3 \mathrm{~h}$, after that, which was naturally cooled to room temperature. Finally, the residue was collected to achieve the modified PR sample. Six PR samples were prepared with different nitrate catalyst (shown in Table 1).

In the experiment, the morphologies of the CNFs formed in phenolic resin were analyzed by field-emission scanning electron microscopy (FESEM, Nova400 NanoSEM). The crystalline phase and the degree of graphitization of the CNFs were examined by X-ray diffraction (XRD, X-pert Pro). 
TABLE 1: Composition of the modified phenolic resin samples.

\begin{tabular}{lccccccc}
\hline Sample number & Reference & (a) & (b) & (c) & (d) & (e) & (f) \\
\hline Phenolic resin/g & 5 & 5 & 5 & 5 & 5 & 5 & 5 \\
Different catalyst & $\backslash$ & $\mathrm{Ni}$ & $\mathrm{Co}$ & $\mathrm{Fe}$ & $\mathrm{Ni} / \mathrm{Co}$ & $\mathrm{Ni} / \mathrm{Fe}$ & $\mathrm{Fe} / \mathrm{Co}$ \\
\hline
\end{tabular}

Note. The mass of catalyst is $0.75 \%$ of the mass of phenolic resin. And mass ratio of the different nitrate in mixture catalysts is $1: 1$.

Thermal gravimetric (TG, STA449C) analysis can be used to characterize the char yield of the phenolic resin modified with carbon nanofibers through weight loss rate in different temperatures.

\section{Results and Discussion}

3.1. FESEM Analysis. To obtain the original morphology of PR sample, the cross-sections of PR samples were chosen randomly. Figures 1 and 2 showed the typical morphologies of the CNFs formed in the modified PR with different catalysts. It was found that a large number of carbon nanofibers were grown out from the carbon pore network during the pyrolysis of phenolic resin (see insert Figure 1(a)). The CNFs formed in the sample (b) were long $(\approx 6 \sim 8 \mu \mathrm{m})$, curly, and twining, while the CNFs formed in the sample (c) were short $(\approx 1 \sim 3 \mu \mathrm{m})$, straight, and sparse. The length, diameter, and aggregation degree of the CNFs formed in the sample (a) were between the samples (b) and (c), which may be related to the activity of three catalysts.

The FESEM and REM photographs of the PR samples with mixed catalysts (Figures $1(\mathrm{~d})-1(\mathrm{f})$ ) showed that the CNFs in the sample (d) were serious wound and agglomerate. The CNFs' diameters of the sample (e) increased to about $0.15 \sim 0.30 \mu \mathrm{m}$, while their distribution became sparse (Figure 1(e)). Compared with a single catalyst, the mixed catalysts $\left(\mathrm{Co}\left(\mathrm{NO}_{3}\right)_{2} / \mathrm{Fe}\left(\mathrm{NO}_{3}\right)_{3}\right)$ can promote the growth of the CNFs in PR, which exhibited the characteristics of large amount, homogeneous dispersion, and nonagglomeration (Figure 1(f)).

3.2. XRD Analysis. Figure 3 showed the XRD patterns of the modified PR with different catalyst. Graphite phase was found in all modified PR samples, which can be distinguished according to the diffraction peaks at $26.4^{\circ}$ and $54.7^{\circ}$ (JCPDS number 40-1487). The result suggested that graphite-like structure appeared in phenolic resin at $1100^{\circ} \mathrm{C}$, which can be verified by FESEM analysis, that is, a large amount of CNFs formed in phenolic resin. In the modified PR samples with a single catalyst, the diffraction peak intensity values of the sample (c), (a), and (b) showed a decreasing trend. It was indicated that the CNFs in the PR with $\mathrm{Fe}\left(\mathrm{NO}_{3}\right)_{3}$ catalyst had higher crystallinity, and amorphous carbon structures are less in the PR.

Compared with the modified PR samples using a single nitrate as catalyst, the diffraction peak intensity values of the sample (d), (e), and (f) were increasing significantly. It showed that the mixed catalysts can promote the CNFs' growth and decrease amorphous carbon structures.
Among them, the peak intensity of the modified PR with $\mathrm{Co}\left(\mathrm{NO}_{3}\right)_{2} / \mathrm{Fe}\left(\mathrm{NO}_{3}\right)_{3}$ catalyst was the highest. It was due to the large amounts of homogeneous dispersion and nonagglomeration CNFs in the phenolic resin (see Figure 1(f)).

3.3. TG Analysis. Figure 4 is the TG analysis of the modified PR with different catalysts. According to Figure 4, the values of weight loss rates of the modified PR samples with different catalysts were calculated and shown in Table 2. It was shown that the reference PR (without catalyst) began weight loss at about $80^{\circ} \mathrm{C}$; however, all modified PR samples appeared smaller weight loss at about $200^{\circ} \mathrm{C}$.

At about $600^{\circ} \mathrm{C}$, the weight loss rate of reference sample was up to $80 \%$; the weight loss rate of sample (a) was about $72 \%$; the weight loss rates of sample (b) and (c) reduced to $35 \%$ and $12 \%$; the weight loss rates of the other samples (i.e., $\mathrm{d}, \mathrm{e}$, and $\mathrm{f}$ ) were less. It may be related to the growth of CNFs in PR. The nitrate catalyst can decompose and generate active metal $\mathrm{Co}, \mathrm{Ni}$, and $\mathrm{Fe}$ particles at high temperature. Taking $\mathrm{Ni}\left(\mathrm{NO}_{3}\right)_{2}$, for example, specific chemical reactions are shown as follows:

$$
\begin{aligned}
2 \mathrm{Ni}\left(\mathrm{NO}_{3}\right)_{2} & =2 \mathrm{NiO}+4 \mathrm{NO}_{2}+\mathrm{O}_{2} \\
\mathrm{NiO}+\mathrm{CO} & =\mathrm{Ni}+\mathrm{CO}_{2}
\end{aligned}
$$

These active metals ( $\mathrm{Co}, \mathrm{Ni}$, and $\mathrm{Fe}$ ) can capture the gases (i.e., $\mathrm{CH}_{4}$ and $\mathrm{CO}$ ) produced in the pyrolysis process of phenolic resin at high temperature and catalytic crack the gases to form CNFs [15]. This reaction process can effectively improve char yield of $\mathrm{PF}$.

At about $700^{\circ} \mathrm{C}$, all of the samples have obvious weight loss. Reference sample stopped weightlessness at $640^{\circ} \mathrm{C}$; samples (a) and (b) stopped weightlessness at around $700^{\circ} \mathrm{C}$; samples (c), (d), and (e) stopped weightlessness at around $750^{\circ} \mathrm{C}$; sample (f) stopped weightlessness at around $833^{\circ} \mathrm{C}$. The trend of the weightlessness of PR may be related to the structure and morphology of the CNFs in modified PR samples (Figure 1). Since the oxidation reaction usually starts from the defect position of CNFs [16], it can be suggested that high crystallinity of CNFs can promote the oxidation resistance of $\mathrm{PR}$ in high temperature.

\section{Conclusions}

(1) Compared with the traditional external addition methods, the in situ formation of CNFs can transform the glassy isotropic carbon during the pyrolysis of phenolic resin catalytic to graphitic carbon by catalytic graphitization. Moreover, the formed CNFs can uniformly disperse in PR and effectively reduce carbon losses and improve char yield of phenolic resin.

(2) Among $\mathrm{Fe}\left(\mathrm{NO}_{3}\right)_{3}, \mathrm{Ni}\left(\mathrm{NO}_{3}\right)_{3}$, and $\mathrm{Co}\left(\mathrm{NO}_{3}\right)_{2}$ catalysts, $\mathrm{Fe}\left(\mathrm{NO}_{3}\right)_{3}$ can effectively improve the stacking-thickness and dimensions of six-membered ring carbon layer of the carbonized product and promote the closer arrangement of carbon atoms. This result can help improve the crystallinity of the CNFs formed in phenolic resins.

(3) Compared with a single catalyst, the mixed catalysts $\left(\mathrm{Co}\left(\mathrm{NO}_{3}\right)_{2}: \mathrm{Fe}\left(\mathrm{NO}_{3}\right)_{3}=1: 1\right)$ can promote the growth of the 


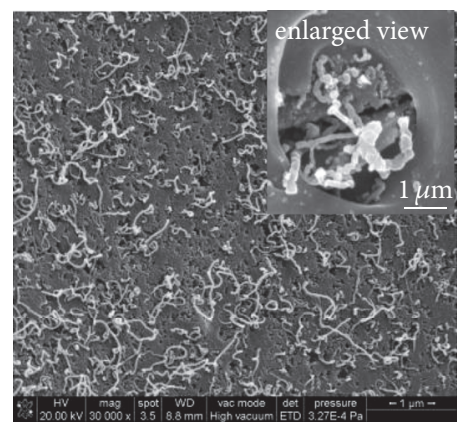

(a)

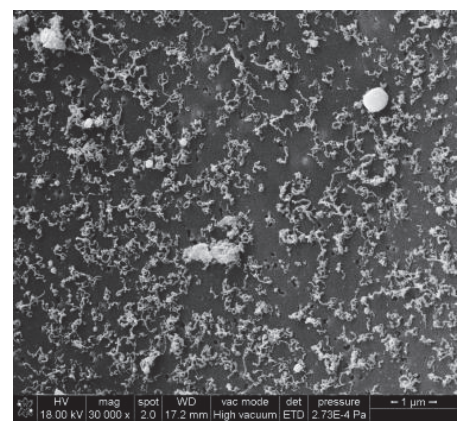

(d)

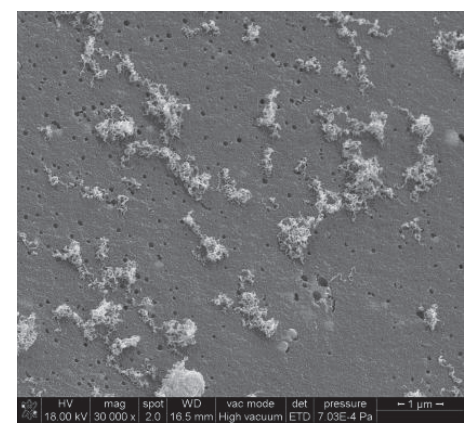

(b)

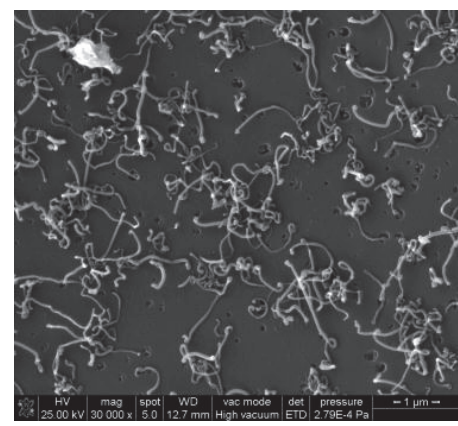

(e)

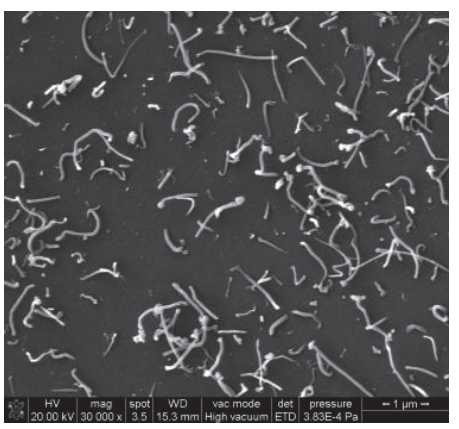

(c)

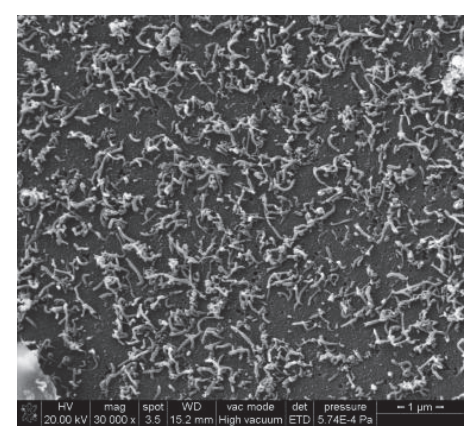

(f)

FIGURE 1: FESEM images of the modified PR with different catalysts.

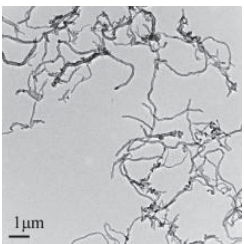

(a)

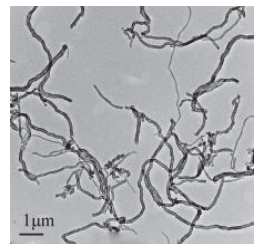

(b)

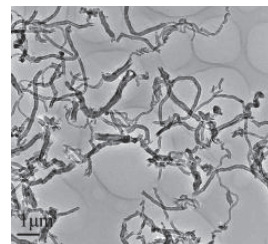

(c)

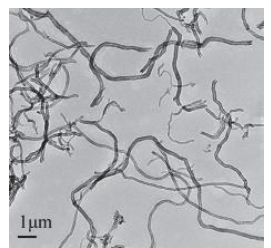

(d)

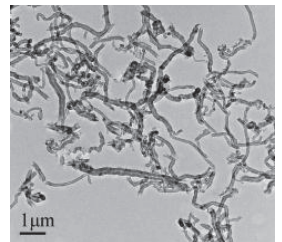

(e)

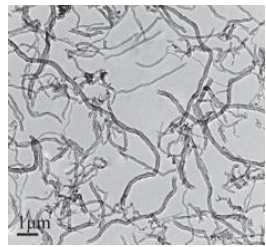

(f)

FIGURE 2: TEM images of the modified PR with different catalysts.
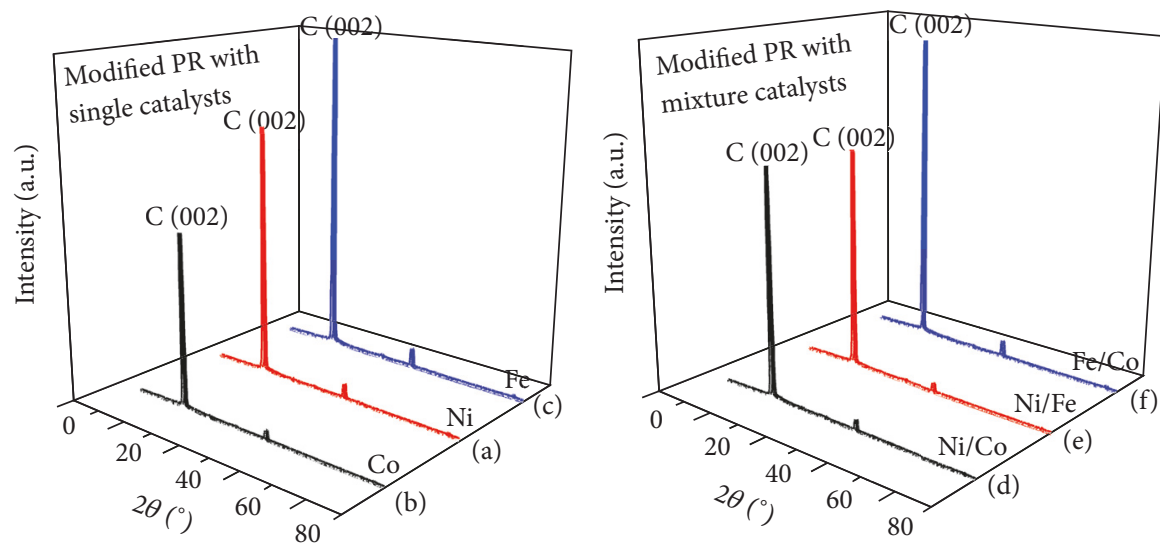

FIGURE 3: XRD patterns of the modified PR with different catalysts. 
TABLE 2: Weight loss rates of the modified PR.

\begin{tabular}{lccccc}
\hline \multirow{2}{*}{ Sample } & \multirow{2}{*}{ Catalyst } & \multicolumn{4}{c}{ Weight loss rate/\% } \\
& & $200^{\circ} \mathrm{C}$ & $400^{\circ} \mathrm{C}$ & $600^{\circ} \mathrm{C}$ & $800^{\circ} \mathrm{C}$ \\
\hline Reference & $\backslash$ & 93.03 & 93.38 & 21.21 & 4.71 \\
(a) & $\mathrm{Ni}$ & 99.30 & 99.20 & 29.37 & 3.88 \\
(b) & $\mathrm{Co}$ & 98.41 & 98.59 & 63.69 & 3.33 \\
(c) & $\mathrm{Fe}$ & 97.70 & 97.28 & 83.89 & 1.63 \\
(d) & $\mathrm{Ni} / \mathrm{Co}$ & 98.32 & 98.33 & 86.98 & 6.24 \\
(e) & $\mathrm{Ni} / \mathrm{Fe}$ & 99.18 & 99.21 & 91.81 & 2.54 \\
(f) & $\mathrm{Fe} / \mathrm{Co}$ & 96.46 & 96.20 & 89.88 & 8.46 \\
\hline
\end{tabular}

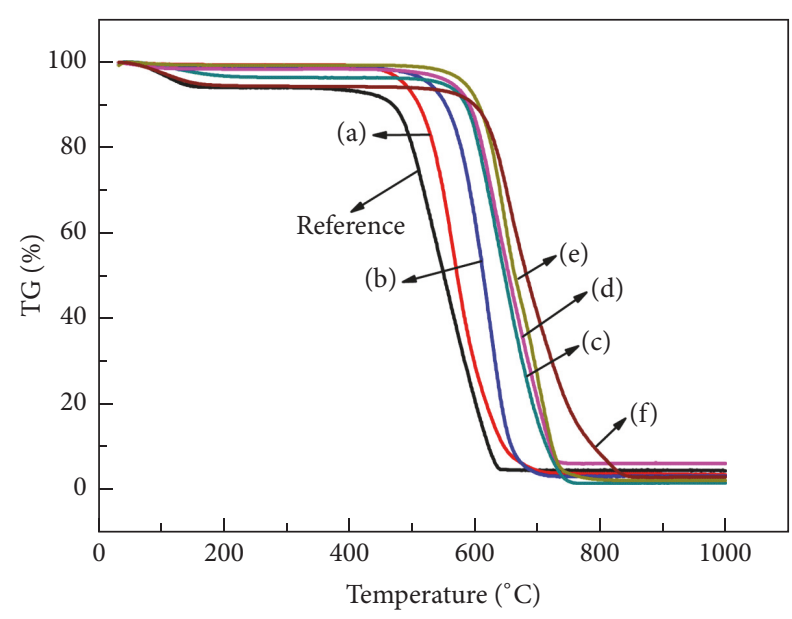
(a) $\mathrm{Ni}$
(d) $\mathrm{Ni} / \mathrm{Co}$
(b) $\mathrm{Co}$
(e) $\mathrm{Ni} / \mathrm{Fe}$
(c) $\mathrm{Fe}$
(f) $\mathrm{Fe} / \mathrm{Co}$

FIgURE 4: TG plots of the modified PR.

carbon nanofibers, which have the characteristics of higher crystallinity, homogeneous dispersion, and nonagglomeration.

\section{Conflicts of Interest}

The authors declare that they have no conflicts of interest.

\section{Acknowledgments}

This work was partially funded by the Natural Science Foundation of Hubei China (Youth Fund, no. 2015CFB517) and the Youth Found of State Key Laboratory of Refractories and Metallurgy (no. 2014QN08).

\section{References}

[1] N. Li, Z. H. Gu, and H. Z. Zhao, Refractory Materials Science, Metallurgical Industry Press, Beijing, China, 2010, (in Chinese).

[2] E. Mohoamed and M. Ewais, "Carbon based refractories," Journal of the Ceramic Society of Japan, vol. 112, pp. 517-532, 2004.

[3] B. Hashemi, Z. A. Nemati, and M. A. Faghihi-Sani, "Effects of resin and graphite content on density and oxidation behavior of
MgO-C refractory bricks," Ceramics International, vol. 32, no. 3, pp. 313-319, 2006.

[4] Q. Hu, X. Wang, and Z. Wang, "Preparation of graphitic carbon nanofibres by in situ catalytic graphitisation of phenolic resins," Ceramics International, vol. 39, no. 7, pp. 8487-8492, 2013.

[5] Z. Adolf, P. Suchánek, and I. Husar, "The influence of carbon content on the corrosion of MGO-C refractory material caused by acid and alkaline ladle slag," Materials and Technology, vol. 42, pp. 131-133, 2008.

[6] Y. Zhang, S. Shen, and Y. Liu, "The effect of titanium incorporation on the thermal stability of phenol-formaldehyde resin and its carbonization microstructure," Polymer Degradation and Stability, vol. 98, no. 2, pp. 514-518, 2013.

[7] F. Taheri-Behrooz, B. Memar Maher, and M. M. Shokrieh, "Mechanical properties modification of a thin film phenolic resin filled with nano silica particles," Computational Materials Science, vol. 96, pp. 411-415, 2015.

[8] Z. Bu, J. Hu, and B. Li, "Novel silicon-modified phenolic novolac resins: non-isothermal curing kinetics, and mechanical and thermal properties of their biofiber-reinforced composites," Thermochimica Acta, vol. 575, pp. 244-253, 2014.

[9] Y. Ding, H. Alias, D. Wen, and R. A. Williams, "Heat transfer of aqueous suspensions of carbon nanotubes (CNT nanofluids)," International Journal of Heat and Mass Transfer, vol. 49, no. 1-2, pp. 240-250, 2006.

[10] S. Berber, Y.-K. Kwon, and D. Tománek, "Unusually high thermal conductivity of carbon nanotubes," Physical Review Letters, vol. 84, no. 20, pp. 4613-4616, 2000.

[11] J. Kong, H. T. Soh, A. M. Cassell, C. F. Quate, and H. Dai, "Synthesis of individual single-walled carbon nanotubes on patterned silicon wafers," Nature, vol. 395 , no. 6705 , pp. $878-$ 881, 1998.

[12] M. Svenngsson, R.-E. Morjan, A. O. Nerushev et al., "Spectroscopy and field-emission properties of CVD-grown carbonnanotube films," Applied Physics A: Materials Science \& Processing, vol. 73, pp. 409-418, 2001.

[13] V. Roungos and C. G. Aneziris, "Improved thermal shock performance of $\mathrm{Al}_{2} \mathrm{O}_{3}-\mathrm{C}$ refractories due to nanoscaled additives," Ceramics International, vol. 38, no. 2, pp. 919-927, 2012.

[14] S. Tamura, T. Ochiai, T. Matsui, and K. Goto, "Technological philosophy and perspective of nanotech refractories," Nippon Steel Technical Report, vol. 98, pp. 18-28, 2008.

[15] R. B. Mathur, B. P. Singh, T. L. Dhami et al., "Influence of carbon nanotube dispersion on the mechanical properties of phenolic resin composites," Polymer Composites, vol. 31, no. 2, pp. 321327,2010

[16] N.-H. Tai, M.-K. Yeh, and J.-H. Liu, "Enhancement of the mechanical properties of carbon nanotube/phenolic composites using a carbon nanotube network as the reinforcement," Carbon, vol. 42, no. 12-13, pp. 2774-2777, 2004. 

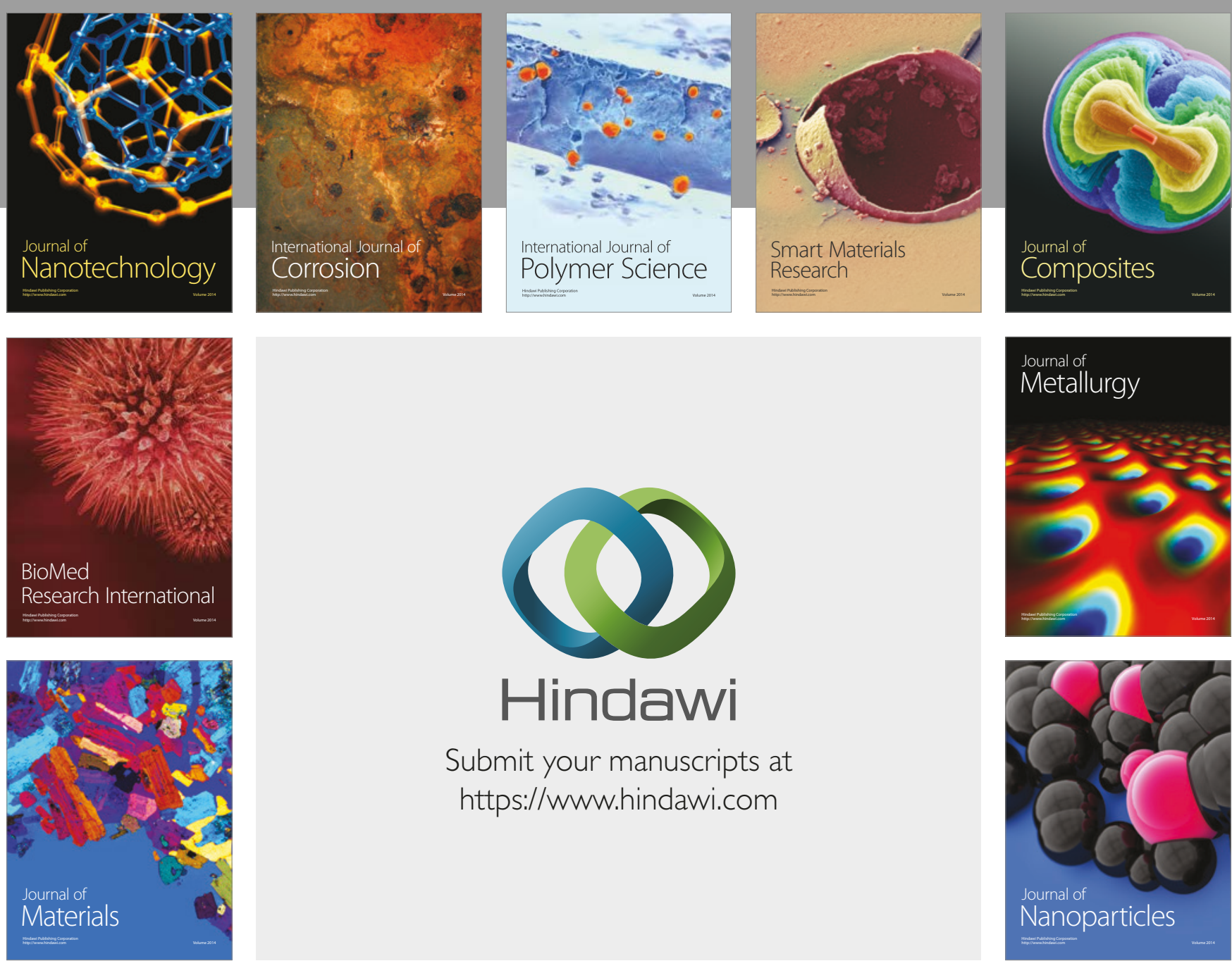

\section{Hindawi}

Submit your manuscripts at

https://www.hindawi.com
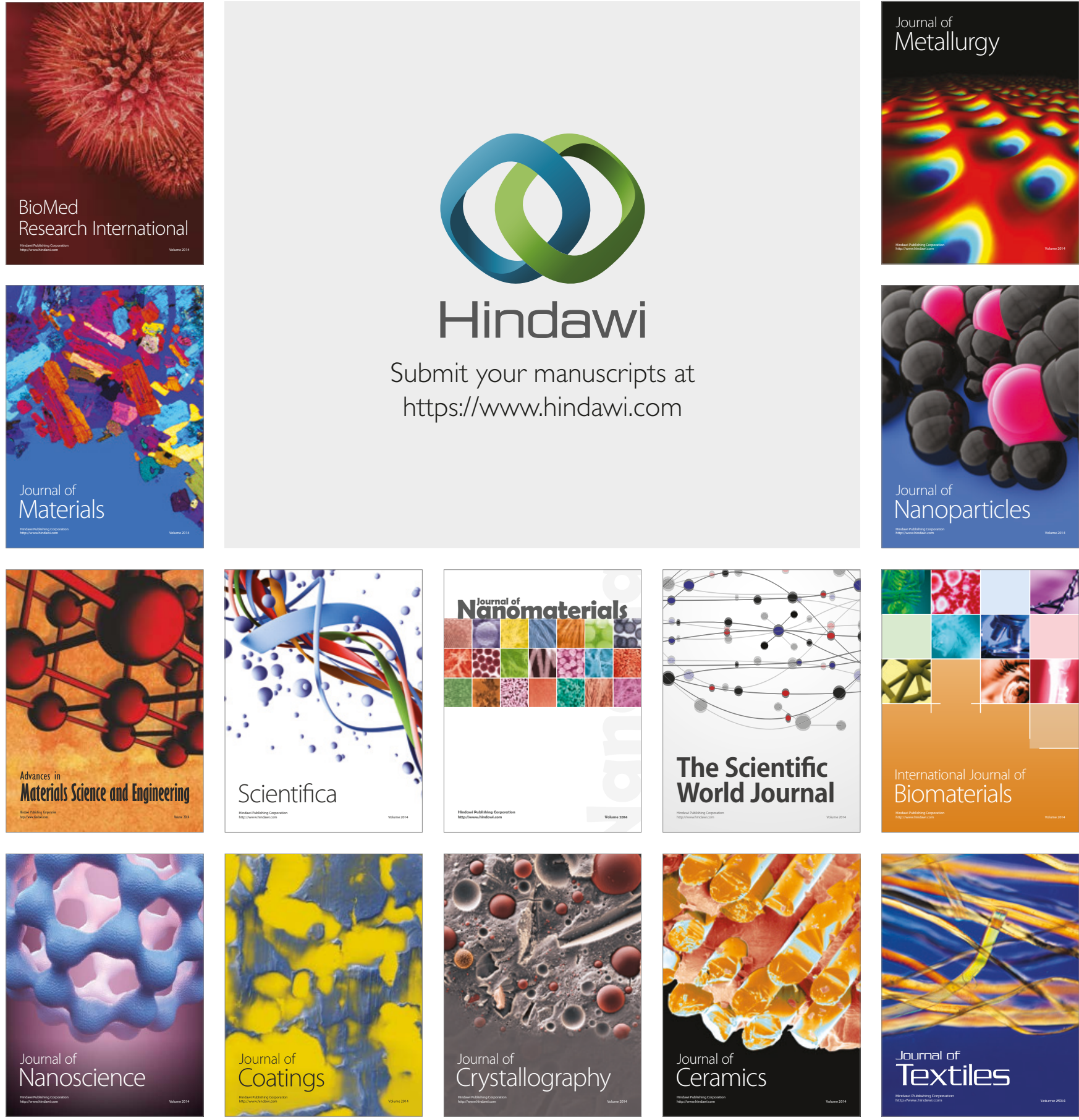

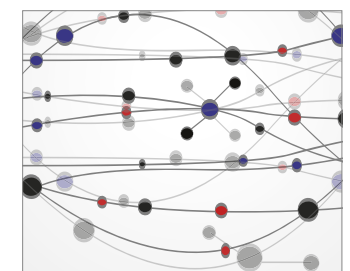

The Scientific World Journal
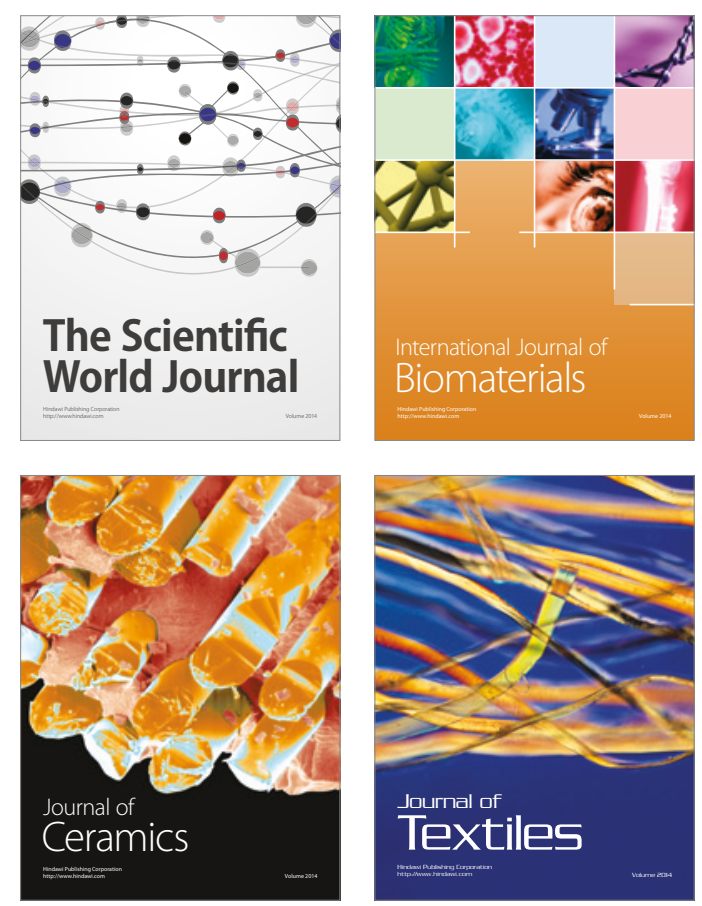